\title{
CORRIGENDUM
}

\section{MiR-186 inhibited aerobic glycolysis in gastric cancer via $\mathrm{HIF}-1 \alpha$ regulation}

L Liu, Y Wang, R Bai, K Yang and Z Tian

Oncogenesis (2017) 6, e318; doi:10.1038/oncsis.2017.20; published online 17 April 2017

Correction to: Oncogenesis (2016) 5, e224; doi:10.1038/ oncsis.2016.35; published online 9 May 2016

Since the publication of the above article, the authors have realized that both Figure 2c, apoptosis figure of Agomir-186-NC group of SGC7901 cell, and Figure 4c, apoptosis figure of Antagomir-186+shHIF-1a, were wrongly used.

The corrected figures are shown here.

The authors would like to apologize to the readers for any inconvenience this may have caused. (c) (i) Oncogenesis is an open-access journal published by Nature Publishing Group. This work is licensed under a Creative Commons Attribution 4.0 International License. The images or other third party material in this article are included in the article's Creative Commons license, unless indicated otherwise in the credit line; if the material is not included under the Creative Commons license, users will need to obtain permission from the license holder to reproduce the material. To view a copy of this license, visit http://creativecommons.org/licenses/by/4.0/

(C) The Author(s) 2017 a

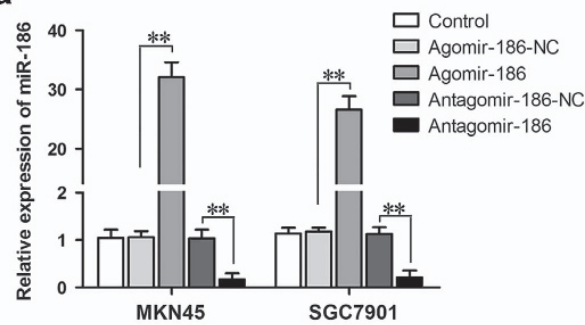

b

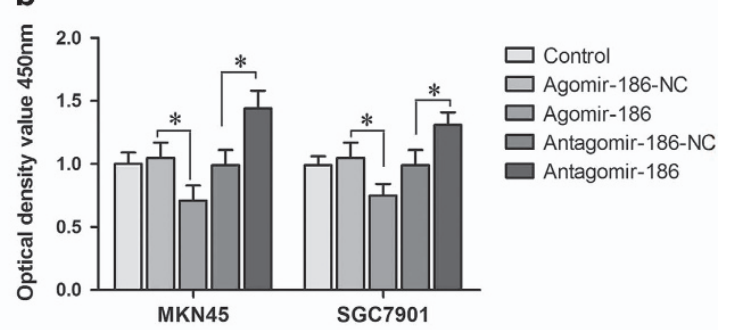

c
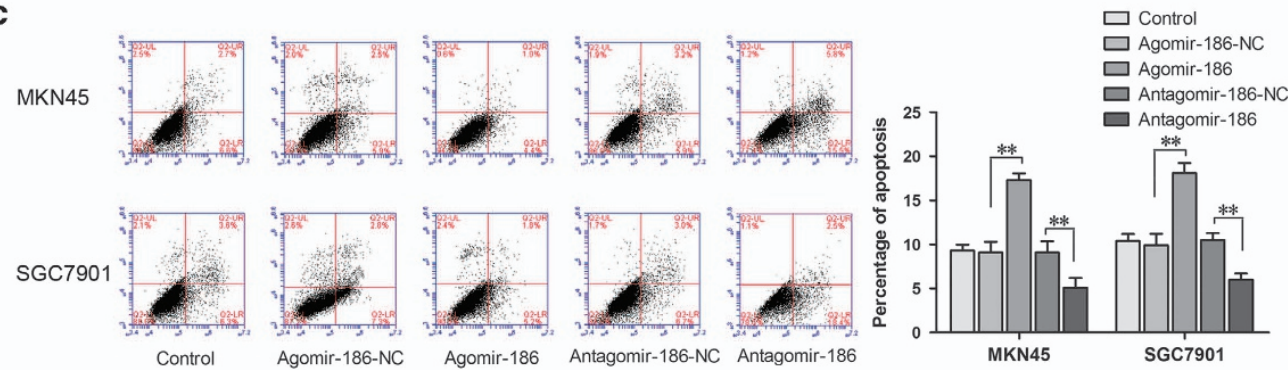
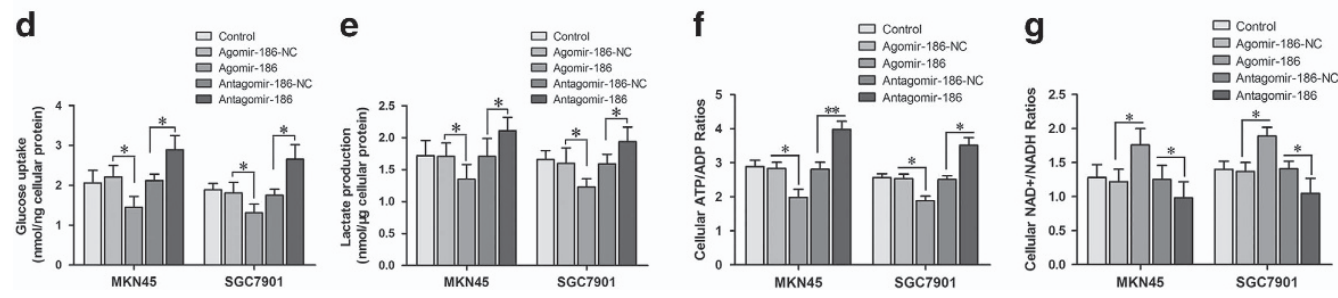

Figure 2 


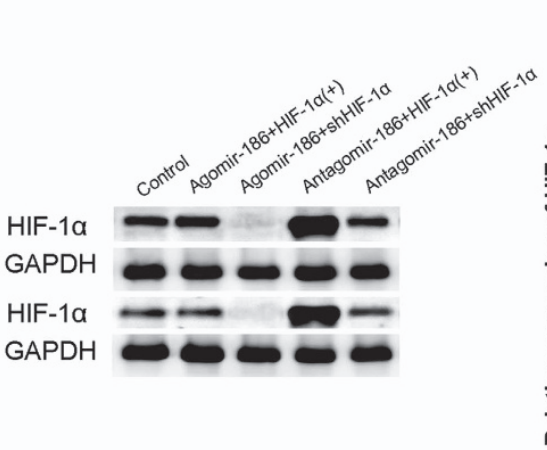

C

MKN45
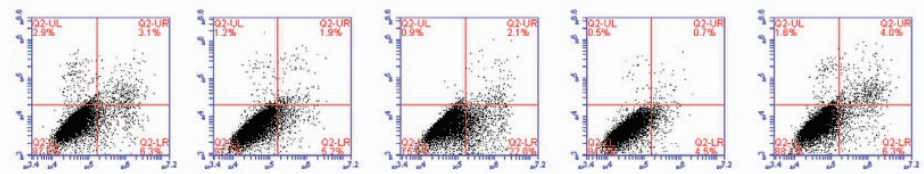

SGC7901
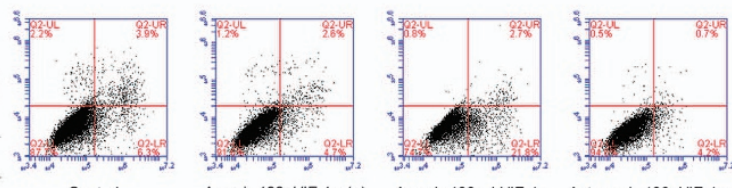

Agomir-186+HIF-1a (+) $\square$ Control

$\square$ Agomir-186+shHIF-1a

$\square$ Antagomir-186+HIF-1 $\alpha(+)$

- Antagomir-186+shHIF-1 $\alpha$

MKN45 $\square$ Agomir-186+HIF-1a (+)

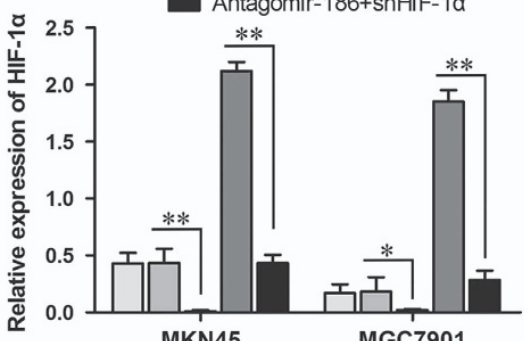

b

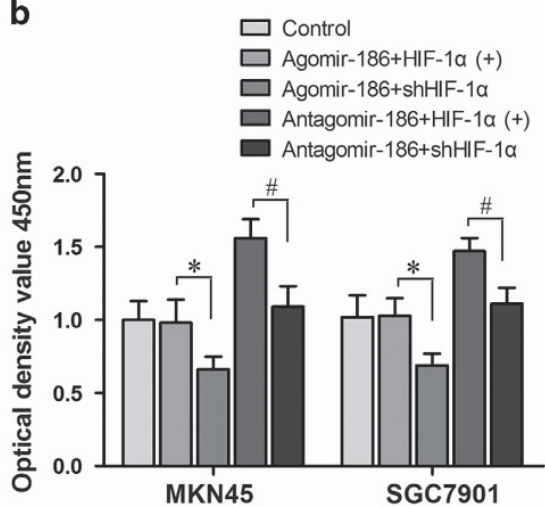

d

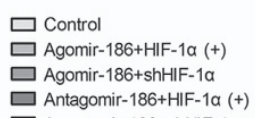

口 Antagomir-186+HIIF-1 $\alpha(+)$

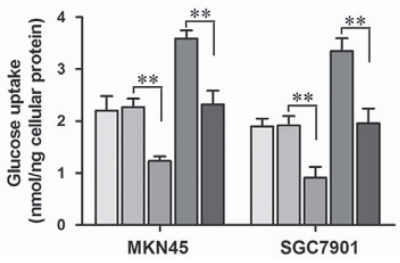

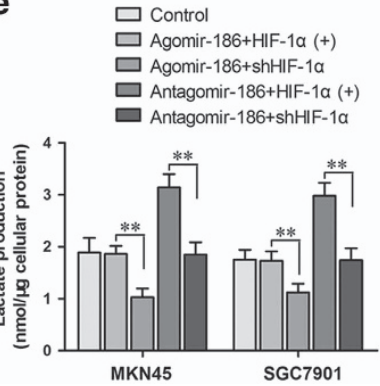

f

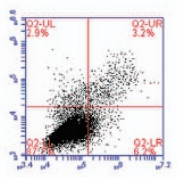

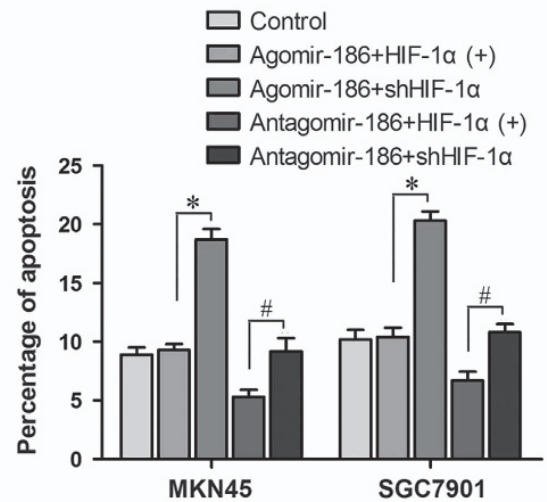

MKN45

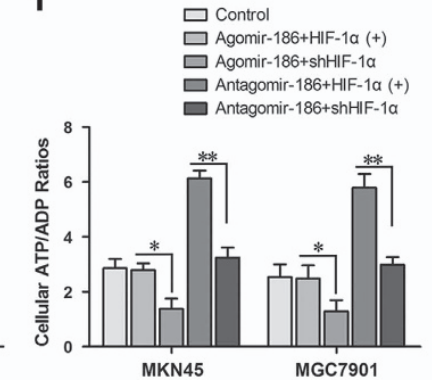

g

Figure 4

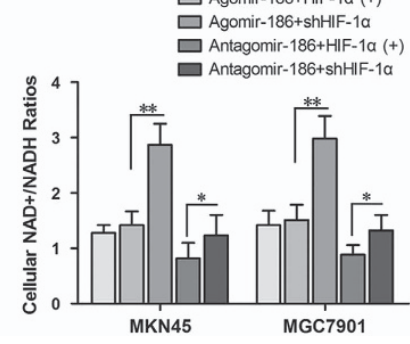

